\title{
Novel ultra-hard hexacarbon allotropes from first principles
}

Samir F. Matar ${ }^{1, \S, *}$ and Vladimir L. Solozhenko ${ }^{2}$

${ }^{1}$ Lebanese German University (LGU), Sahel-Alma, Jounieh, Lebanon.

(D) https://orcid.org/0000-0001-5419-358X

${ }^{2}$ LSPM-CNRS, Université Sorbonne Paris Nord, 93430 Villetaneuse, France.

ib https://orcid.org/0000-0002-0881-9761

${ }^{\S}$ Former DR1-CNRS senior researcher at the University of Bordeaux, ICMCB-CNRS, France

*Corresponding author email: s.matar@lgu.edu.lb and abouliess@gmail.com

\begin{abstract}
Novel ultra-hard carbon allotropes are proposed based on crystal chemistry rationale and geometry optimization onto ground state structures. Like diamond, new orthorhombic, tetragonal, and trigonal $\mathrm{C}_{6}$ are identified as cohesive networks of $C 4$ tetrahedra illustrated by charge density projections exhibiting $\mathrm{sp}^{3}$-like carbon hybridization. The three allotropes are mechanically (elastic constants) and dynamically (phonons) stable. Furthermore, they exhibit thermal properties like those of diamond. The electronic band structures are characteristic of insulators with large band gaps of 4 to $5 \mathrm{eV}$. From four different models evaluating Vickers hardness new carbon allotropes are identified as ultra-hard with $H_{\mathrm{V}}$ close to $95 \mathrm{GPa}$.
\end{abstract}

Keywords: DFT; crystal chemistry; carbon allotropes; ultra-hard materials, thermal properties, phonons. 


\section{Introduction and context}

Until very recently diamond was the only material qualified as ultrahard. Despite its unique properties i.e. extreme hardness, elevated thermal conductivity, large band gap, high electron and hole mobility making it suitable for diverse basic research and applications, the reactivity of diamond with oxygen and ferrous metals constitute a drawback. Furthermore, diamond's hardness drastically drops with temperature. As consequence, there is a growing demand for other advanced materials that stimulated the search for novel ultra-hard thermally and chemically stable phases (cf. [1,2-4] and references therein).

In 2009 ultra-hard diamond-like $\mathrm{BC}_{5}$ was synthesized by Solozhenko et al. [5]. This phase corresponds to the ultimate solubility of boron in diamond and possesses Vickers hardness of $71 \mathrm{GPa}$, unusually high for superhard materials fracture toughness ( 10 MPa $\mathrm{m}^{1 / 2}$ ), and very high (up to $1900 \mathrm{~K}$ ) thermal stability which makes it an exceptional superabrasive superior to diamond. Diamond-like $\mathrm{BC}_{5}$ is metastable phase and can be synthesized only in a narrow temperature range under pressures above $20 \mathrm{GPa}$ which makes its production quite a challenge.

Yao et al. attempted revealing thermodynamic stable polymorphs of $\mathrm{BC}_{5}$ from structural searches combined with first-principles structural optimizations [6]. Besides of tetragonal $(I \overline{4} m 2)$ polymorph, trigonal $(P 3 m 1)$ and triclinic $(P-1)$ forms of $\mathrm{BC}_{5}$ were theoretically predicted. The study revealed mixed stacking of covalent $\mathrm{C}-\mathrm{C}$ and metallic $\mathrm{B}-\mathrm{C}$ substructures with an overall metallic system keeping ultra-hard mechanical properties.

In as far as $\mathrm{BC}_{5}$ can be considered as a B-substituted carbon network, the hypothetic system with full carbon occupancy becomes an extended three-dimensional (3D) carbon, candidate for ultrahardness. Extended 3D carbon networks have gained interest in view of the challenging question: "is diamond the hardest material" as generally admitted? In this context, hexagonal $6 H$ carbon ( $P 6_{3} / m m c$ space group) was claimed to be harder than diamond [7], and we recently discussed the ultra-hardness of a novel rhombohedral carbon allotrope $\left(r h-C_{4}\right)$ [8] which can be considered as an extended hexagonal $h$ - $\mathrm{C}_{12}$ lattice presenting mechanical properties like those of diamond (Vickers hardness $\left.H_{\mathrm{V}} \sim 100 \mathrm{GPa}\right)$.

The present study was carried out within the well-established quantum density functional theory DFT framework $[9,10]$ with the aim to highlight the ultra-hardness along with modern models of novel hexacarbon $\mathrm{C}_{6}$ structures based on three $\mathrm{BC}_{5}$ forms. In particular, the mechanical (elastic constants) and dynamical (phonons bands) stabilities of these phases were confirmed. Furthermore, they are identified with thermal properties alike diamond. Orthorhombic, tetragonal, and trigonal $\mathrm{C}_{6}$ all have energies close to diamond's and are equally characterized by a stacking of $C 4$ tetrahedra. The electronic band structures are shown to exhibit insulating behavior like diamond with large gaps close to $5 \mathrm{eV}$. 


\section{Computational framework}

The search for the ground state structures through geometry optimizations and total energies calculations was performed using the plane-wave Vienna Ab initio Simulation Package (VASP) code $[9,10]$ based on DFT. The projector augmented wave (PAW) method [11,12] was used for the atomic potentials with all valence states, especially in regard of such light element as carbon. DFT exchange-correlation (XC) effects were considered using the generalized gradient approximation (GGA) [14]. For the relaxation of the atoms onto ground state geometry, a conjugate-gradient algorithm [15] was applied. Improved tetrahedron method [16] with corrections according to Methfessel-Paxton scheme [17] was applied for geometry optimization and energy calculations. A special k-point sampling [18] was applied for approximating the reciprocal space Brillouin-zone (BZ) integrals. For better reliability, the optimization of the structural parameters was carried out along with successive self-consistent cycles with increasing mesh until the forces on atoms were less than $0.02 \mathrm{eV} / \AA \AA$ and the stress components below $0.003 \mathrm{eV} / \AA^{3}$.

Besides the elastic constants calculated to infer the mechanical stabilities and hardness, further calculations of phonon dispersion curves were also carried out to verify the dynamic stability of new carbon allotropes. In the present work, the phonon modes were computed considering the harmonic approximation via finite displacements of the atoms around their equilibrium positions to obtain the forces from the summation over the different configurations. The phonon dispersion curves along the direction of the Brillouin zone are subsequently obtained using "Phonopy" interface code based on Python language [19]. Thermodynamic properties such as the Helmholtz free energy, the heat capacity $\mathrm{C}_{\mathrm{v}}$ and the entropy $\mathrm{S}$, were calculated as functions of temperature.

\section{Calculations and results}

\section{1-Energy and crystal symmetry}

The novel $\mathrm{C}_{6}$ structures were derived from the orthorhombic, tetragonal, and trigonal carbon rich $\mathrm{BC}_{5}$ by selective substitutions of boron by carbon leading to the hexacarbon systems. The structures were then geometry optimized to their respective stress-free ground states. The energy is the prevailing criterion for the first assessment of the new structures. The total energies: $\mathrm{E}_{\text {total }}(\mathrm{eV})$ and the derived atom-averaged energies $\mathrm{E}_{\text {atom }}$ are presented in Table 1. Additionally, the results for $r h$ $\mathrm{C}_{4}\left(h-\mathrm{C}_{12}\right)$ [8] and diamond are given. All atom-averaged values of $\mathrm{C}_{6}$ structures are found very close to diamond, thus pointing out their stability, at least with respect to diamond.

The $\mathrm{C}_{6}$ structures are shown in Fig. 1. All three structures exhibit tetrahedral carbon $C 4\left(s p^{3}\right)$ featured with four small yellow sticks stemming from each atom. Such tetrahedral shape is well known to be characteristic of diamond and provides a signature for totally covalent 3D carbon.

The crystal data provided in Table 2 present the converged calculated new atomic positions after full unconstrained geometry optimization with successive calculations at increasing precision of k-mesh in the three respective Brillouin zones. The starting values of the corresponding $\mathrm{BC}_{5}$ from 
Ref. [6] are given in brackets. It can be noticed a clear increase of symmetry upon replacing B by C resulting in remarkable atomic positions and relationships between the atomic coordinates, as highlighted and detailed at the bottom of each part of Table 2. A unique interatomic $\mathrm{C}-\mathrm{C}$ distance of $1.55 \AA$ characteristic of diamond is found for all $\mathrm{C}_{6}$ allotropes.

\section{3-2. Charge density $3 D$ projections}

Further illustration of "electronic $\leftrightarrow$ crystal structure" relationship focusing on the tetrahedral $\mathrm{C}\left(\mathrm{sp}^{3}\right)$-like carbon as the building unit of the novel allotropes, can be provided by the charge density projections. Fig. 2 shows the charge density volumes (yellow) with perfect $\mathrm{sp}^{3}$ tetrahedral shape around carbon. For the two body-centered orthorhombic (Imm2) and body-centered tetragonal $(I \overline{4} m 2)$ allotropes, the primitive cells with 12 carbon atoms are represented. Due to simple trigonal $\mathrm{C}_{6}$ the stacking of tetrahedra is most clearly demonstrated among the three projections, with the tetrahedral yellow volumes.

\section{3-3. Mechanical properties}

\section{(i) Elastic constants}

The investigation of mechanical characteristics was based on the calculations of the elastic properties determined by performing finite distortions of the lattice and deriving the elastic constants from the strain-stress relationship. Most compounds are polycrystalline, and generally considered as randomly oriented single crystalline grains. Consequently, on a large scale, such materials can be considered as statistically isotropic. They are then fully described by bulk $(B)$ and shear $(G)$ moduli obtained by averaging the single-crystal elastic constants. The method used here is Voigt's [20], based on a uniform strain. The calculated sets of elastic constants are given in Table 3. All values are positive. Their combinations obeying the rules pertaining to the mechanical stability of the phase, and the equations providing the bulk $B_{\mathrm{V}}$ and shear $G_{\mathrm{V}}$ moduli are as follows [21].

- For the orthorhombic system:

$$
\begin{gathered}
\mathrm{C}_{\mathrm{ii}}(\mathrm{i}=1,4,5,6)>0 ; \mathrm{C}_{11} \mathrm{C}_{22}-\mathrm{C}_{12}^{2}>0 ; \mathrm{C}_{11} \mathrm{C}_{22} \mathrm{C}_{33}+2 \mathrm{C}_{12} \mathrm{C}_{13} \mathrm{C}_{23}-\mathrm{C}_{11} \mathrm{C}_{23}{ }^{2}-\mathrm{C}_{22} \mathrm{C}_{13}{ }^{2}-\mathrm{C}_{33} \mathrm{C}_{12}{ }^{2}>0 . \\
B_{\text {Voigt }}^{\text {orth. }}=1 / 9\left(\mathrm{C}_{11}+2 \mathrm{C}_{12}+2 \mathrm{C}_{13}+\mathrm{C}_{22}+2 \mathrm{C}_{23}+\mathrm{C}_{33}\right) \\
G_{\text {Voigt }}^{\text {orth. }}=1 / 15\left(\mathrm{C}_{11}-\mathrm{C}_{12}-\mathrm{C}_{13}+\mathrm{C}_{22}-\mathrm{C}_{23}+\mathrm{C}_{33}+3 \mathrm{C}_{44}+3 \mathrm{C}_{55}+6 \mathrm{C}_{44}+3 \mathrm{C}_{66}\right)
\end{gathered}
$$

- For the tetragonal system:

$$
\begin{aligned}
\mathrm{C}_{\mathrm{ii}}(\mathrm{i}=1,3,4,6) & >0 ; \mathrm{C}_{11}>\mathrm{C}_{12}, \mathrm{C}_{11}+\mathrm{C}_{33}-2 \mathrm{C}_{13}>0 ; \text { and } 2 \mathrm{C}_{11}+\mathrm{C}_{33}+2 \mathrm{C}_{12}+4 \mathrm{C}_{13}>0 . \\
B_{\text {Voigt }}^{\text {tetr. }} & =1 / 9\left(2 \mathrm{C}_{11}+\mathrm{C}_{33}+2 \mathrm{C}_{12}+4 \mathrm{C}_{13}\right) . \\
G_{\text {Voigt }}^{\text {tetr. }} & =1 / 15\left(2 \mathrm{C}_{11}+\mathrm{C}_{12}+2 \mathrm{C}_{33}-2 \mathrm{C}_{13}+6 \mathrm{C}_{44}+3 \mathrm{C}_{66}\right) .
\end{aligned}
$$


- For the hexagonal (trigonal) system:

$$
\begin{aligned}
\mathrm{C}_{11}>\mathrm{C}_{12}, \mathrm{C}_{11} \mathrm{C}_{33}>\mathrm{C}_{13}{ }^{2} \text { and }\left(\mathrm{C}_{11}+\mathrm{C}_{12}\right) \mathrm{C}_{33}>2 \mathrm{C}_{13}{ }^{2} \\
B_{\text {Voigt }}^{\text {hex. }}=1 / 9\left\{2\left(\mathrm{C}_{11}+\mathrm{C}_{12}\right)+4 \mathrm{C}_{13}+\mathrm{C}_{33}\right\} \\
G_{\text {Voigt }}^{\text {hex. }}=1 / 30\left\{\mathrm{C}_{11}+\mathrm{C}_{12}+2 \mathrm{C}_{33}-4 \mathrm{C}_{13}+12 \mathrm{C}_{44}+6\left(\mathrm{C}_{11}-\mathrm{C}_{12}\right)\right\}
\end{aligned}
$$

The calculated values for all three $C_{6}$ carbon allotropes in Table 3 exhibit large $B_{\mathrm{V}}(>400 \mathrm{GPa}$ ) and $G_{\mathrm{V}}(>500 \mathrm{GPa})$ values that are comparable with the accepted values for diamond. Such results allow assigning ultra-hard mechanical properties to the novel carbon allotropes and extracting hardness-related properties as developed in the next subsection.

\section{(ii) Hardness}

Vickers hardness $\left(H_{\mathrm{V}}\right)$ was predicted using four pertinent theoretical models of hardness [22-25]. The thermodynamic model [22] is based on thermodynamic properties and crystal structure, while Mazhnik-Oganov [24] and Chen-Niu [25] models use the elastic properties. Lyakhov-Oganov approach [23] considers topology of the crystal structure, strength of covalent bonding, degree of ionicity and directionality. The fracture toughness $\left(\mathrm{K}_{\mathrm{Ic}}\right)$ was evaluated within the Mazhnik-Oganov model [24].

The results are summarized in Tables 4 and 5. Table 4 presents Vickers hardness and bulk moduli $\left(B_{0}\right)$ calculated in the framework of the thermodynamic model of hardness. Table 5 presents hardness calculated using four different theoretical models and other mechanical properties such as shear modulus $(G)$, Young's modulus $(E)$, the Poisson's ratio $(v)$ and fracture toughness $\left(\mathrm{K}_{\mathrm{Ic}}\right)$.

A slightly lower hardness of $h-\mathrm{C}_{6}$ and $r h-\mathrm{C}_{3}$ compared to diamond (both cubic and hexagonal) is observed for both models (Table 4). On the other hand, hardness of these phases is much higher than hardness of the vast majority of recently predicted carbon allotropes $\left(C_{14}, C_{16}, C_{24}, C_{36}\right.$, etc.) [29-33].

A good agreement of the bulk moduli of three new $\mathrm{C}_{6}$ allotropes and $r h-\mathrm{C}_{4}$ [8] estimated using the thermodynamic model $\left(B_{0}\right)$ and calculated from the set of elastic constants $\left(B_{\mathrm{V}}\right)$ is observed. For all three phases $\mathrm{K}_{\mathrm{Ic}}$ is almost twice higher than the $2.8 \mathrm{MPa} \cdot \mathrm{m}^{1 / 2}$ value for single-crystal cubic BN [34] and close to the experimental value of diamond fracture toughness (5 MPa $\mathrm{m}^{1 / 2}$ ) [35].

Thus, all three $\mathrm{C}_{6}$ allotropes have exceptional mechanical properties among all recently proposed carbon allotropes [29-33] and thus can be considered as prospective ultra-hard materials [1].

\section{3-4. Dynamical stabilities from the phonons.}

Beside structural stability criteria obeyed by all three new carbon phases through the positive magnitudes of the elastic constants and their combinations, we computed the phonon modes. 
Phonons, quanta of vibrations, have their energy quantized - just like photons - through the Planck constant ' $h$ ' used in its reduced form $\hbar(\hbar=h / 2 \pi)$ giving with the wave number $\omega$ the energy: $E=\hbar \omega$.

Following the method presented in Section 2, the obtained phonon band structures for three new $\mathrm{C}_{6}$ phases are shown in Fig. 3. In each panel along the horizontal direction, the bands run along the main lines of orthorhombic (Fig. 3a), tetragonal (Fig. 3b) and hexagonal (Fig. 3c) Brillouin zones. Along the vertical direction the frequencies are given in units of terahertz (THz). Since no negative frequency magnitudes are observed, all three $\mathrm{C}_{6}$ structures can be considered as dynamically stable. There are 3N-3 optical modes at high energy and 3 acoustic modes. The two body-centered orthorhombic (Imm2) and tetragonal (I $\overline{4} \mathrm{~m} 2$ ) allotropes were accounted for using primitive cells with 12 carbon atoms, whence the larger number of bands versus trigonal $\mathrm{C}_{6}$ (Fig. 3c). The acoustic modes start from zero energy $(\omega=0)$ at the $\Gamma$ point, center of the Brillouin Zone, up to a few Terahertz. They correspond to the lattice rigid translation modes of the crystal (two transverse and one longitudinal). Then 30 bands are expected in Figs. 3a and 3b, and 15 bands in Fig. 3c. But knowing that the higher the symmetry, the more dispersion curves showing degeneracy are found for a given frequency, an apparent reduction in the number of dispersion curves is observed. In the three panels the energy range is the same for all three phases, i.e. from 0 to $40 \mathrm{THz}$, stressing furthermore their similitude with the magnitude observed for diamond by Raman spectroscopy: $\omega \sim 40 \mathrm{THz}[36]$.

\section{3-5. Thermal properties.}

After the phonon band structures, the thermal properties such as free energy, entropy and heat capacity $C_{v}$ were calculated using the statistical thermodynamic expressions from the phonon frequencies on a high precision sampling mesh in the BZ (cf. the textbook by Dove on 'Lattice Dynamics' [37]). All three allotropes were found to present similar curves. Fig. 4 shows the temperature change of entropy and heat capacity at constant volume, and he Helmholtz free energy: $\mathrm{F}=\mathrm{U}$-TS where U stands for the internal energy and S for entropy. The plots are shown in two panels for diamond and trigonal $\mathrm{C}_{6}$ as representative of all hexacarbon allotropes.

For the two phases, the free energy decreases with temperature as expected from the equation above because $S$ increases with $\mathrm{T}$ almost linearly as it can be seen in both panels. In Fig. 4a, the entropy $\mathrm{S}$ and the heat capacity are close to zero up to $100 \mathrm{~K}$. Above $100 \mathrm{~K}$, S increases continuously and almost linearly up to the highest temperatures. For the heat capacity curves, a validation of the evolution of $\mathrm{C}_{\mathrm{v}}$ was found from experimental data on diamond's heat capacity up to high temperatures obtained by Victor back in 1962 [38]. The discrete experimental points obtained from 300K up to $1000 \mathrm{~K}$ by steps of $100 \mathrm{~K}$ are plotted as open symbols on the calculated curve (green). An excellent agreement can be observed, except for the last two points at the highest temperature. While supporting our calculated results, this feature is interesting and may raise the remark as to the stability of the measurements and of diamond sample at such high temperatures. 
Fig. 4b shows results for trigonal hexacarbon showing similarity with diamond. For the sake of comparison, the experimental points from [38] were reported. Up to $700 \mathrm{~K}$, the heat capacity of $\mathrm{C}_{6}$ is higher than that of diamond, while at higher temperatures the curve follows the experimental points for diamond with the same feature (as in Fig. 4a) for the last two points departing from the curve.

\subsection{Electronic band structures.}

Fig. 5 shows the electronic band structures for three new $\mathrm{C}_{6}$ allotropes obtained using the allelectrons DFT-based augmented spherical method (ASW) [39]. The energy level along the vertical line is with respect to the top of the valence band $(\mathrm{VB}), \mathrm{E}_{\mathrm{V}}$. The $\mathrm{VB}$ is largely separated from the empty conduction band CB by a large band gap amounting to $\sim 5 \mathrm{eV}$. Such insulating electronic character resembles diamond. A few features relevant to the nature of the band gap can be observed such as the indirect in orthorhombic and hexagonal (trigonal) $\mathrm{C}_{6}$, like in diamond but identified as indirect between $\Gamma_{\mathrm{VB}}$ and $\Gamma_{\mathrm{CB}}$ in tetragonal $\mathrm{C}_{6}$ allotrope.

Acknowledgments: Computational facilities from the University of Bordeaux and from the Lebanese German University are gratefully acknowledged.

Author Contributions: Samir F. Matar: Structure conceptualization. Software. Computations. Vladimir L. Solozhenko: Hardness evaluation. Expertise in hard materials.

Funding: This research received no external funding.

Data Availability Statement: Data supporting reported results including CIF files can be made available on demand.

Conflicts of Interest. The authors declare no conflict of interest. 


\section{REFRENCES}

[1] V.L. Solozhenko, Y. Le Godec, A hunt for ultrahard materials. J. Appl. Phys. 126, 230401 (2019).

[2] V.L. Solozhenko, High-pressure synthesis of novel superhard phases. in: "Comprehensive Hard Materials" (eds. V.K. Sarin and C.E. Nebel), Elsevier, 2014, pp. 641-652.

[3] Y. Le Godec, A. Courac, V. L. Solozhenko, High-pressure synthesis of superhard and ultrahard materials. J. Appl. Phys. 126, 151102 (2019).

[4] S.F. Matar, V.L. Solozhenko, Crystal chemistry and ab initio prediction of ultrahard rhombohedral $\mathrm{B}_{2} \mathrm{~N}_{2}$ and $\mathrm{BC}_{2} \mathrm{~N}$. Solid State Sci. 118, 106667 (2021).

[5] V.L. Solozhenko, O.O. Kurakevych, D. Andrault, Y. Le Godec, M. Mezouar, Ultimate metastable solubility of boron in diamond: Synthesis of superhard diamondlike $\mathrm{BC}_{5}$. Phys. Rev. Lett. 102, 015506 (2009).

[6] Y. Yao, J.S. Tse, D.D. Klug, Crystal and electronic structure of superhard BC5: Firstprinciples structural optimizations. Phys. Rev. B 80, 094106 (2009).

[7] F. Gao, J. Zhanga, Z. Lia, Origin of ultrahardness of $6 \mathrm{H}$ diamond: harder than cubic diamond. RSC Adv. 4, 32345-32347 (2014).

[8] S.F. Matar, V.L. Solozhenko, Ultra-hard rhombohedral carbon from crystal chemistry rationale and first principles. J. Solid State Chem. 302, 122354 (2021).

[9] P. Hohenberg, W. Kohn, Inhomogeneous electron gas. Phys. Rev. B 136, 864-871 (1964).

[10] W. Kohn, L.J. Sham, Self-consistent equations including exchange and correlation effects. Phys. Rev. A 140, 1133-1138 (1965).

[11] G. Kresse, J. Furthmüller, Efficient iterative schemes for ab initio total-energy calculations using a plane-wave basis set. Phys. Rev. B 54, 11169 (1996).

[12] G. Kresse, J. Joubert, From ultrasoft pseudopotentials to the projector augmented wave. Phys. Rev. B 59, 1758-1775 (1999).

[13] P.E. Blöchl, Projector augmented wave method. Phys. Rev. B 50, 17953-17979 (1994).

[14] J. Perdew, K. Burke, M. Ernzerhof, The Generalized Gradient Approximation made simple. Phys. Rev. Lett. 77, 3865-3868 (1996).

[15] W.H. Press, B.P. Flannery, S.A. Teukolsky, W.T. Vetterling, Numerical Recipes, $2^{\text {nd }}$ ed. Cambridge University Press: New York, USA, 1986.

[16] P.E. Blöchl, O. Jepsen, O.K. Anderson, Improved tetrahedron method for Brillouin-zone integrations. Phys. Rev. B 49, 16223-16233 (1994).

[17] M. Methfessel, A.T. Paxton, High-precision sampling for Brillouin-zone integration in metals. Phys. Rev. B 40, 3616-3621(1989). 
[18] H.J. Monkhorst, J.D. Pack, Special k-points for Brillouin Zone integration. Phys. Rev. B 13, 5188-5192 (1976).

[19] A. Togo, I. Tanaka, First principles phonon calculations in materials science. Scr. Mater. 108, 1-5 (2015).

[20] W. Voigt, Über die Beziehung zwischen den beiden Elasticitätsconstanten isotroper Körper. Annal. Phys. 274, 573-587 (1889).

[21] D.C. Wallace, Thermodynamics of crystals. New York, USA: John Wiley and Sons; 1972.

[22] V.A. Mukhanov, O.O. Kurakevych, V.L. Solozhenko, The interrelation between hardness and compressibility of substances and their structure and thermodynamic properties. J. Superhard Mater., 30, 368-378 (2008).

[23] A.O. Lyakhov, A.R. Oganov, Evolutionary search for superhard materials: Methodology and applications to forms of carbon and $\mathrm{TiO}_{2}$. Phys. Rev. B 84, 092103 (2011).

[24] E. Mazhnik, A.R. Oganov, A model of hardness and fracture toughness of solids. J. Appl. Phys., 126, 125109 (2019).

[25] X-Q.Chen, H. Niu, D. Li, Y. Li, Modeling hardness of polycrystalline materials and bulk metallic glasses. Intermetallics, 19, 1275-1281 (2011).

[26] P.D. Ownby, X. Yang, J. Liu, Calculated X-ray diffraction data for diamond polytypes. J. Am. Ceram. Soc. 75, 1876-1883 (1992).

[27] N. Bindzus, T. Straasø, N. Wahlberg, J. Becker, L. Bjerg, N. Lock, A.-C. Dippel, B.B. Iversen Experimental determination of core electron deformation in diamond. Acta Cryst. A 70, 39-48 (2014).

[28] V.V. Brazhkin, V.L. Solozhenko, Myths about new ultrahard phases: Why materials that are significantly superior to diamond in elastic moduli and hardness are impossible. J. Appl. Phys. 125, 130901 (2019).

[29] D. D. Pang, X.Q. Huang, H.Y. Xue, C. Zhang, Z.L. Lv, M.Y. Duan, Properties of a predicted tetragonal carbon allotrope: first principles study. Diam. Relat. Mater. 82, 50-55 (2018).

[30] W. Zhang, C. Chai, Q. Fan, Y. Song, Y. Yang, Metallic and semiconducting carbon allotropes comprising of pentalene skeletons. Diam. Relat. Mater. 109, 108063 (2020).

[31] X. Yang, C. Lv, S. Liu, J. Zang, J. Qin, M. Du, D. Yang, X. Li, B. Liu, C.-X. Shan, Orthorhombic $\mathrm{C}_{14}$ carbon: A novel superhard $\mathrm{sp}^{3}$ carbon allotrope. Carbon 156, 309312(2020).

[32] Q. Fan, H. Liu, L. Jiang, X. Yu, W. Zhang, S. Yun, Two orthorhombic superhard carbon allotropes: $\mathrm{C}_{16}$ and $\mathrm{C}_{24}$. Diam. Relat. Mater. 116, 108426 (2021).

[33] Q. Fan, H. Liu, R. Yang, X. Yu, W. Zhang, S. Yun, An orthorhombic superhard carbon allotrope: Pmma C24. J. Solid State Chem. 300, 122260 (2021). 
[34] V.L. Solozhenko, S.N. Dub, N.N. Novikov, Mechanical properties of cubic $\mathrm{BC}_{2} \mathrm{~N}$, a new superhard phase. Diam. Relat. Mater. 10, 2228-2231 (2001).

[35] N.V. Novikov, S.N. Dub, Fracture toughness of diamond single crystals. J. Hard Mater. 2, 3-11 (1991).

[36] R.S. Krishnan, Raman spectrum of diamond. Nature 155, 171 (1945).

[37] M.T. Dove, Introduction to lattice dynamics, Cambridge University Press, 1993.

[38] A.C. Victor, Heat capacity of diamond at high temperatures, J. Chem. Phys. 36 (1962) 19031911.

[39] V. Eyert, Basic notions and applications of the augmented spherical wave method. Int. J. Quantum Chem. 77, 1007-1031 (2000). 
Table 1 Total and atom averaged energies of different carbon allotropes considered in present work. Energies are in $\mathrm{eV}$ units, $\mathrm{Z}$ is number of formula units.

\begin{tabular}{lllll}
\hline Carbon phase & Space group / $\mathrm{N}^{\circ}$ & $\mathrm{E}_{\text {total }}$ & E/atom & $\mathrm{Z}$ \\
\hline $\mathrm{C}_{6}$ (orthorhombic) & $I m m 2\left(\mathrm{~N}^{\circ} 44\right)$ & -109.14 & -9.095 & 2 \\
$\mathrm{C}_{6}$ (tetragonal) & $I \overline{4} m 2\left(\mathrm{~N}^{\circ} 119\right)$ & -109.08 & -9.090 & 2 \\
$\mathrm{C}_{6}$ (trigonal) & $P 3 m 1\left(\mathrm{~N}^{\circ} 156\right)$ & -54.57 & -9.095 & 1 \\
$\mathrm{C}_{12}\left(r h-\mathrm{C}_{4}\right)[8]$ & $R \overline{3} m\left(\mathrm{~N}^{\circ} 166\right)$ & -109.08 & -9.090 & 1 \\
$\mathrm{C}_{8}($ diamond $)$ & $F d \overline{3} m\left(\mathrm{~N}^{\circ} 227\right)$ & -72.72 & -9.090 & 4
\end{tabular}


Table 2 Crystal parameters from DFT calculation of the hexacarbon $\mathrm{C}_{6}$ structures. Values in brackets are from the corresponding $\mathrm{BC}_{5}$ forms [6].

a) Orthorhombic $\mathrm{C}_{6}$, space group $\operatorname{Imm} 2$ ( $\left.\mathrm{N}^{\circ} 44\right)$. (Fig. 1a).

$a=7.579 \AA ; b=2.527 ; c=3.574 \AA . \quad(\mathrm{Z}=2)$

\begin{tabular}{lllll}
\hline Atom & Wyckoff & $\mathrm{x}$ & $\mathrm{y}$ & \multicolumn{1}{c}{$\mathrm{z}$} \\
\hline C1 & $2 b$ & $1 / 2$ & 0.0 & $* 0.042(0.023)$ \\
C2 & $4 c$ & $1 / 6(0.1725)$ & 0.50 & $* 0.292(0.2835)$ \\
C3 & $4 c$ & $1 / 6(0.1686)$ & 0.0 & $* * 0.042(0.0419)$ \\
C4 & $2 a$ & 0.0 & 0.0 & $* * 0.792(0.826)$
\end{tabular}

$\mathrm{d}(\mathrm{C}-\mathrm{C})=1.55 \AA$.

* $0.292-0.042=1 / 4$

** $0.792-0.042=3 / 4$

b) Tetragonal $\mathrm{C}_{6}$, space group $I \overline{4} m 2$ ( $\left.\mathrm{N}^{\circ} 119\right)$. (Fig. 1b).

$a=b=2.519 \AA ; c=10.690 \AA$. $(\mathrm{Z}=2)$

\begin{tabular}{lclll}
\hline Atom & Wyckoff & $\mathrm{x}$ & $\mathrm{y}$ & $\mathrm{z}$ \\
\hline $\mathrm{C} 1$ & $2 d$ & 0.50 & 0.0 & $1 / 4$ \\
$\mathrm{C} 2$ & $4 e$ & 0.0 & 0.0 & $1 / 6(0.1568)$ \\
$\mathrm{C} 3$ & $2 b$ & 0.0 & 0.0 & 0.50 \\
$\mathrm{C} 4$ & $4 f$ & 0.0 & 0.50 & $1 / 12(0.0805)$ \\
\hline
\end{tabular}

$\mathrm{d}(\mathrm{C}-\mathrm{C})=1.55 \AA$.

c) Trigonal $\mathrm{C}_{6}$, space group $P 3 m 1$ ( $\mathrm{N}^{\circ}$ 156). (Fig. 1c).

$a=b=2.521 \AA ; c=6.180 \AA$. $(\mathrm{Z}=1)$.

\begin{tabular}{lcccl}
\hline Atom & Wyckoff & $\mathrm{x}$ & $\mathrm{y}$ & \multicolumn{1}{c}{$\mathrm{z}$} \\
\hline $\mathrm{C} 1$ & $1 a$ & 0.0 & 0.0 & $0.0(0.0069)$ \\
$\mathrm{C} 2$ & $1 a$ & 0.0 & 0.0 & $1 / 4(0.2598)$ \\
$\mathrm{C} 3$ & $1 b$ & $1 / 3$ & $2 / 3$ & $1 / 3(0.3386)$ \\
$\mathrm{C} 4$ & $1 b$ & $1 / 3$ & $2 / 3$ & $* 0.584(0.581)$ \\
$\mathrm{C} 5$ & $1 c$ & $2 / 3$ & $1 / 3$ & $2 / 3(0.5818)$ \\
C5 & $1 c$ & $2 / 3$ & $1 / 3$ & $* \underline{0.917(0.664)}$ \\
& & & & \\
\hline
\end{tabular}

$\mathrm{d}(\mathrm{C}-\mathrm{C})=1.55 \AA$.

$* 0.917=1 / 3+0.584$ 
Table 3 Elastic constants $C_{\mathrm{ij}}$ and Voigt values of bulk $\left(B_{\mathrm{V}}\right)$ and shear $\left(G_{\mathrm{V}}\right)$ moduli of new carbon allotropes (all values are in GPa).

\begin{tabular}{lccccccccc}
\hline & $\mathrm{C}_{11} / \mathrm{C}_{22}$ & $\mathrm{C}_{12}$ & $\mathrm{C}_{13} \mathrm{C}_{23}$ & $\mathrm{C}_{33}$ & $\mathrm{C}_{44}$ & $\mathrm{C}_{55}$ & $\mathrm{C}_{66}$ & $B_{\mathrm{V}}$ & $G_{\mathrm{V}}$ \\
\hline $\mathrm{C}_{6}(\mathrm{Imm} 2)$ & $1204 / 1206$ & 43 & $148 / 149$ & 1101 & 476 & 570 & 580 & 465 & 536 \\
\hline $\mathrm{C}_{6}(\bar{I} \overline{4} \mathrm{~m} 2)$ & $1172 / 1173$ & 28 & $134 / 134$ & 1069 & 465 & 437 & 570 & 438 & 502 \\
\hline $\mathrm{C}_{6}(P 3 m 1)$ & 1171 & 99 & 63 & 1205 & 536 & 501 & - & 444 & 542 \\
\hline
\end{tabular}


Table 4 Vickers hardness $\left(H_{\mathrm{V}}\right)$ and bulk moduli $\left(B_{0}\right)$ of carbon allotropes calculated in the framework of the thermodynamic model of hardness ${ }^{*}$

\begin{tabular}{|c|c|c|c|c|c|c|c|}
\hline & Space group & $a(\AA)$ & $b(\AA)$ & $c(\AA)$ & $\rho\left(\mathrm{g} / \mathrm{cm}^{3}\right)$ & $H_{\mathrm{V}}(\mathrm{GPa})$ & $B_{0}(\mathrm{GPa})$ \\
\hline $\mathrm{C}_{6}(\# 44)$ & $I m m 2$ & 7.5799 & 2.5266 & 3.5740 & 3.4967 & 97 & 440 \\
\hline $\mathrm{C}_{6}(\# 119)$ & $I \overline{4} m 2$ & 2.5187 & 2.5187 & 10.6900 & 3.5293 & 98 & 445 \\
\hline $\mathrm{C}_{6}(\# 156)$ & $P 3 m 1$ & 2.5214 & 2.5214 & 6.1800 & 3.5172 & 97 & 443 \\
\hline$r h-C_{4}[8]$ & $R \overline{3} m$ & 2.5004 & 2.5004 & 12.210 & 3.6204 & 100 & 456 \\
\hline Lonsdaleite & $P 63 / m m c$ & $2.5221^{\dagger}$ & $2.5221^{\dagger}$ & $4.1186^{\dagger}$ & 3.5164 & 97 & 443 \\
\hline Diamond & $F d \overline{3} m$ & $3.5666^{\ddagger}$ & - & - & 3.5169 & 98 & $445^{\S}$ \\
\hline
\end{tabular}

* Ref. 22

$\dagger$ Ref. 26

$\ddagger$ Ref. 27

$\S$ Ref. 28 
Table 5 Mechanical properties of carbon allotropes: Vickers hardness $\left(H_{\mathrm{V}}\right)$, bulk modulus $(B)$, shear modulus $(G)$, Young's modulus $(E)$, Poisson's ratio $(v)$ and fracture toughness $\left(K_{\text {Ic }}\right)$

\begin{tabular}{|c|c|c|c|c|c|c|c|c|c|c|}
\hline & \multicolumn{4}{|c|}{$H_{\mathrm{V}}$} & \multicolumn{2}{|c|}{$B$} & \multirow{2}{*}{$G_{\mathrm{V}}$} & \multirow{2}{*}{$E^{* *}$} & \multirow{2}{*}{$v^{* *}$} & \multirow{2}{*}{$K_{\text {Ic }}^{\ddagger}$} \\
\hline & $\mathrm{T}^{*}$ & $\mathrm{LO}^{\dagger}$ & $\mathrm{MO}^{\ddagger}$ & $\mathrm{CN}^{\S}$ & $B_{0}^{*}$ & $B_{\mathrm{V}}$ & & & & \\
\hline & \multicolumn{6}{|c|}{$\mathrm{GPa}$} & & & & $\mathrm{MPa} \cdot \mathrm{m}^{1 / 2}$ \\
\hline $\mathrm{C}_{6}(\operatorname{Imm} 2)$ & 97 & 89 & 101 & 90 & 440 & 465 & 536 & 1162 & 0.084 & 6.8 \\
\hline $\mathrm{C}_{6}(I \overline{4} m 2)$ & 98 & 90 & 95 & 86 & 445 & 438 & 502 & 1090 & 0.085 & 6.1 \\
\hline $\mathrm{C}_{6}(P 3 m 1)$ & 97 & 90 & 103 & 97 & 443 & 444 & 542 & 1156 & 0.066 & 6.5 \\
\hline$r h-\mathrm{C}_{4}[8]$ & 100 & $93^{\dagger \dagger}$ & 105 & 97 & 456 & 458 & 552 & 1181 & 0.070 & 6.7 \\
\hline Lonsdaleite & 97 & 90 & 99 & 94 & 443 & 432 & 521 & 1115 & 0.070 & 6.2 \\
\hline Diamond & 98 & 90 & 100 & 93 & & & $530^{\ddagger \ddagger}$ & 1138 & 0.074 & 6.4 \\
\hline
\end{tabular}

* Thermodynamic model [22]

† Lyakhov-Oganov model [23]

‡ Mazhnik-Oganov model [24]

$\S$ Chen-Niu model [25]

${ }^{* *} E$ and $v$ values calculated using isotropic approximation

${ }^{\dagger+}$ Calculated in present work

抹 Ref. 28 

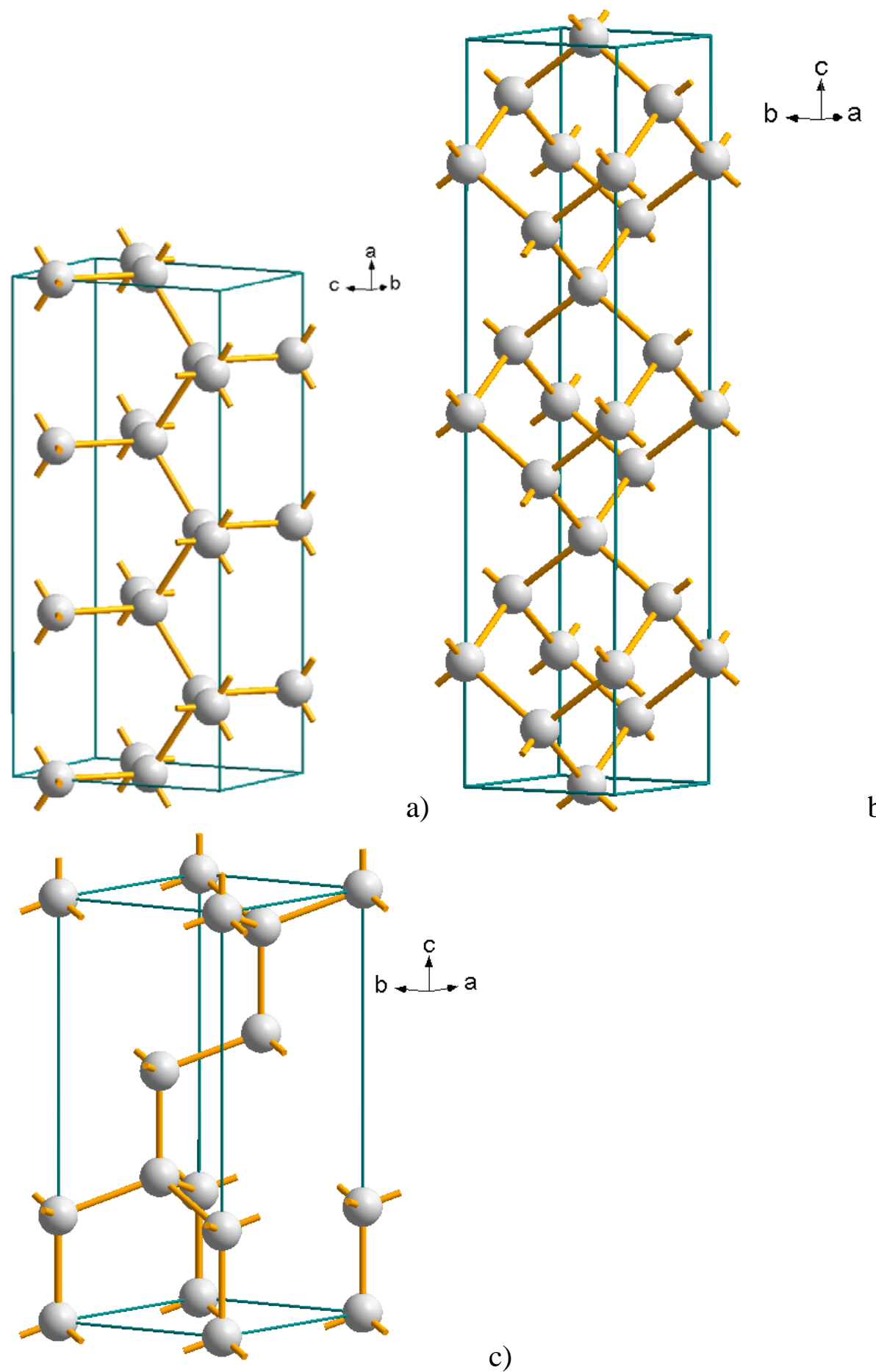

b)

c)

Fig. 1 Structure sketches of three novel $\mathrm{C}_{6}$ allotropes: a) orthorhombic (Imm2); b) tetragonal ( $(\overline{4} m 2)$; c) trigonal $(P 3 m 1)$. The tetrahedral coordination is seen with the yellow-orange sticks on each grey sphere carbon atoms. 

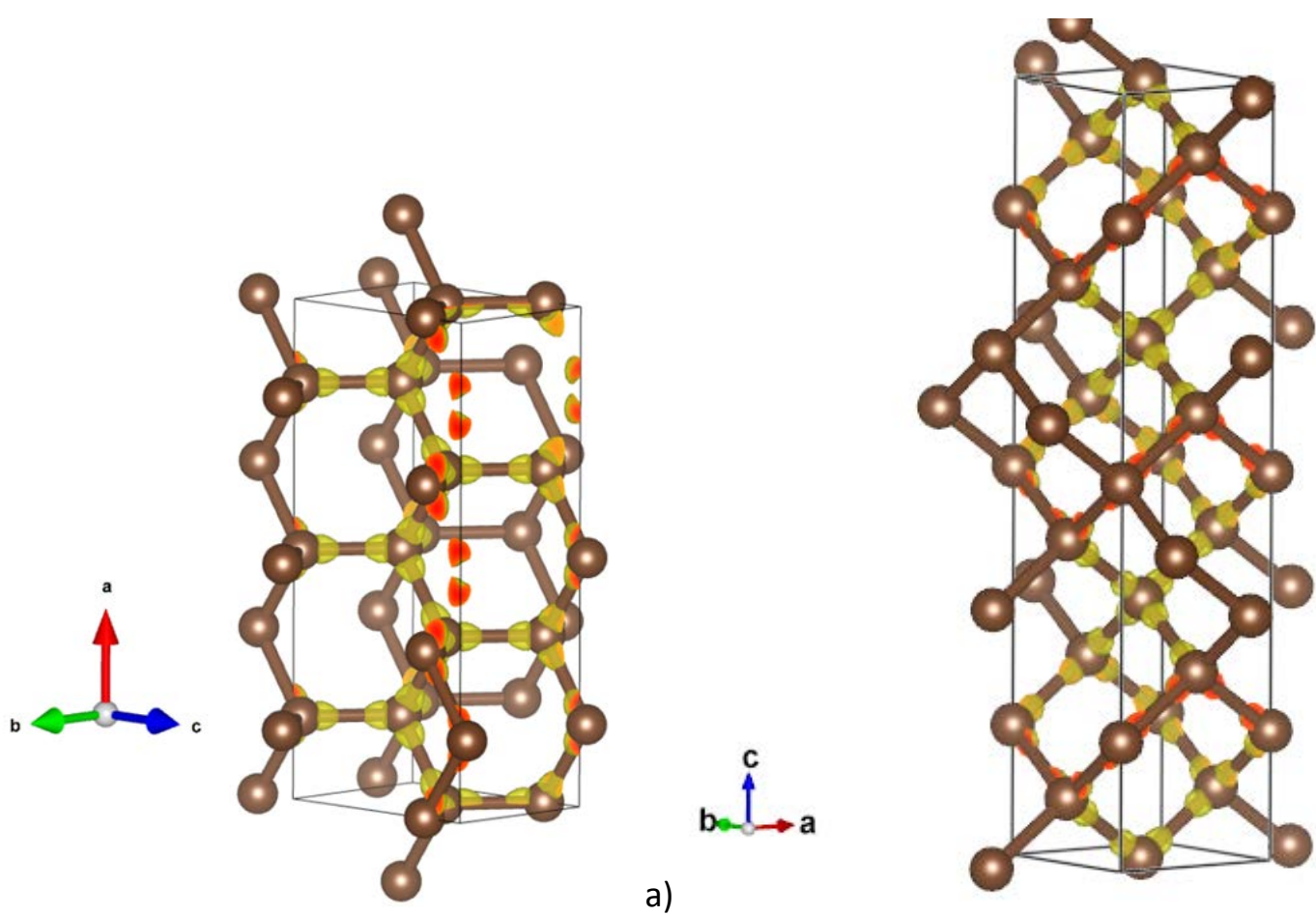

a)

b)

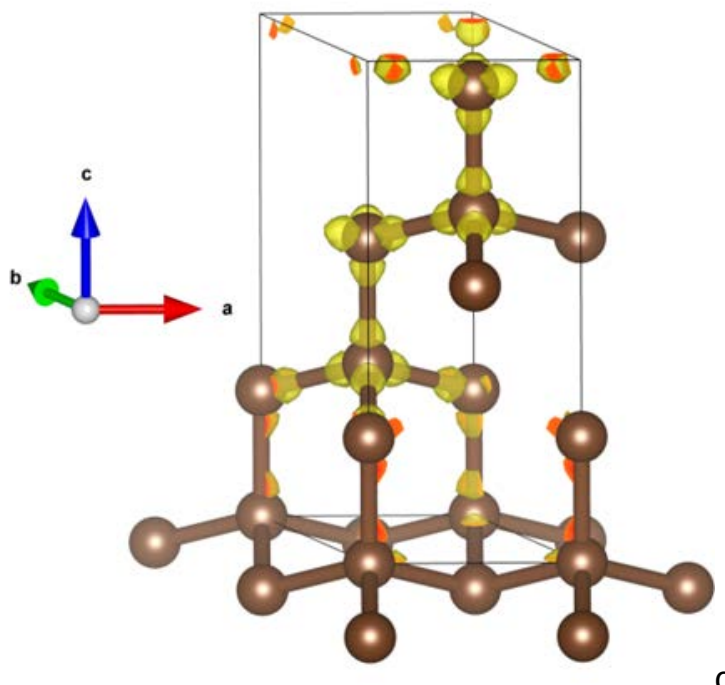

c)

Fig. 2 Charge density yellow volumes around carbon atoms shows tetrahedral $\mathrm{sp}^{3}$-like shapes in a) $\mathrm{C}_{6}$ in simple orthorhombic cell (i.e. $\mathrm{C}_{12}$ ); b) $\mathrm{C}_{6}$ in simple tetragonal cell (i.e. $\mathrm{C}_{12}$ ); and c) trigonal $\mathrm{C}_{6}$. 


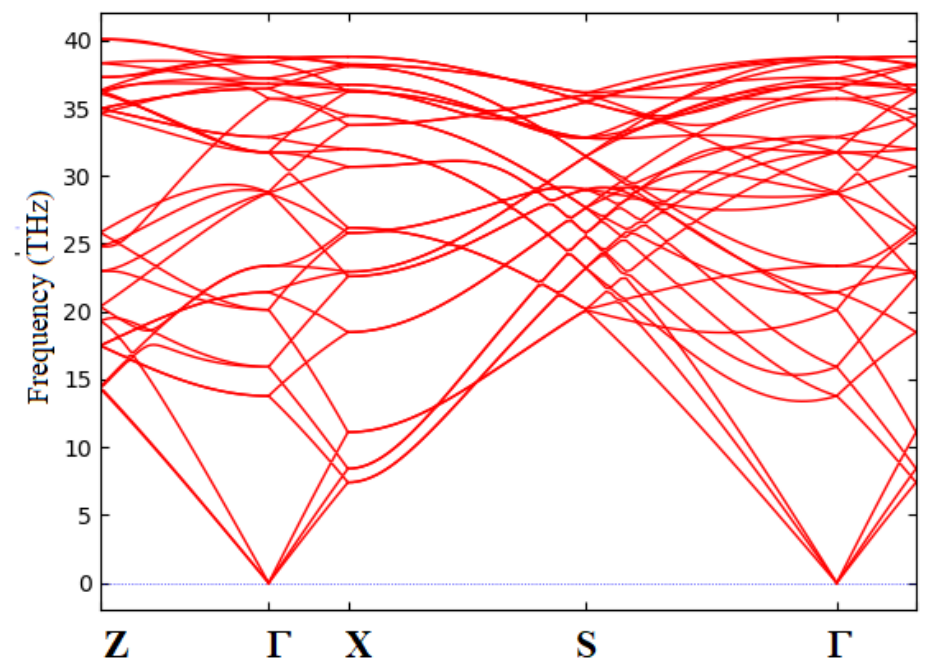

a)
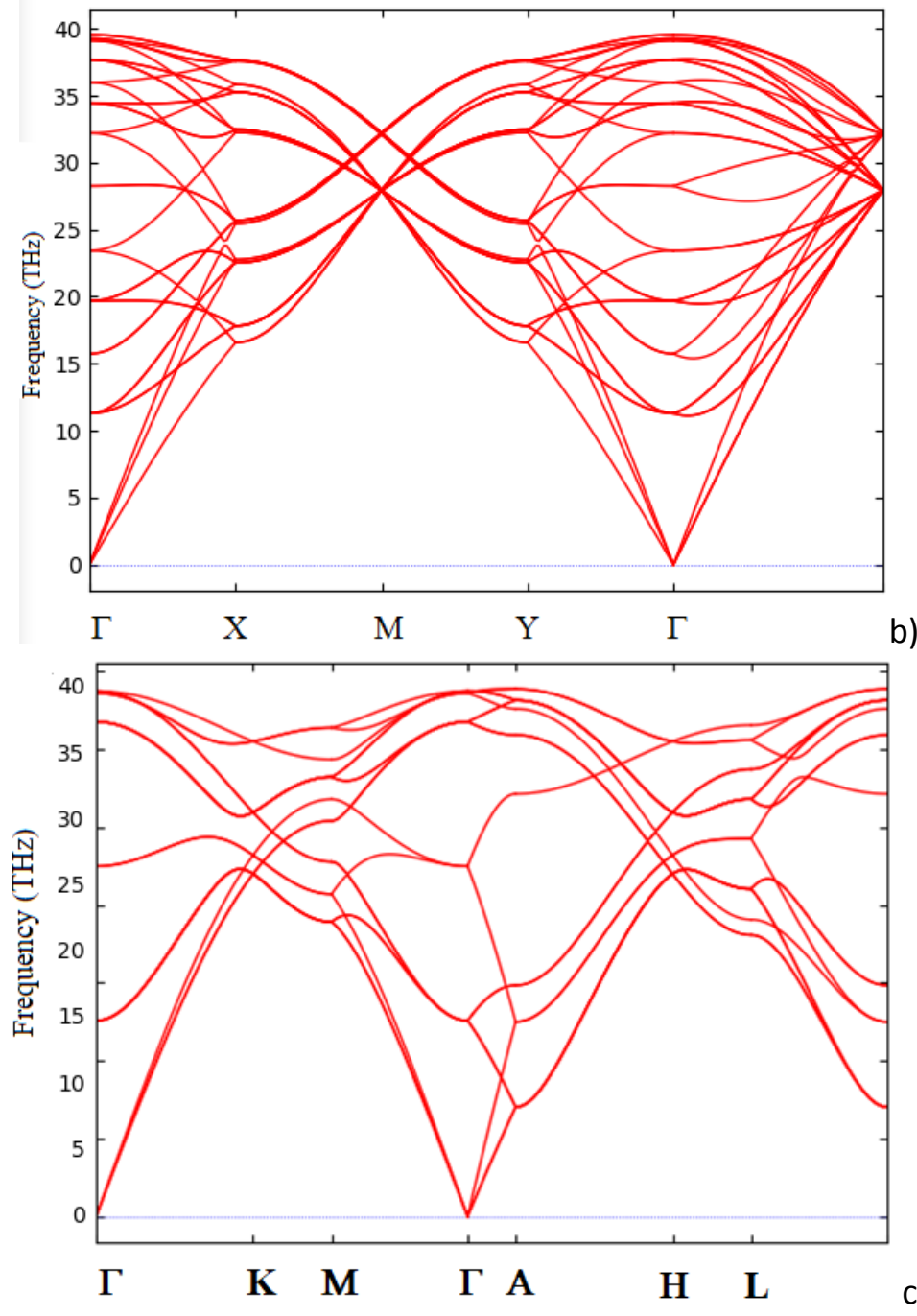

Fig. 3 Phonon band structures along the lines of the different Brillouin zones (along horizontal direction): a) orthorhombic $\mathrm{C}_{6}$, b) tetragonal $\mathrm{C}_{6}, \mathrm{c}$ ) trigonal $\mathrm{C}_{6}$. 


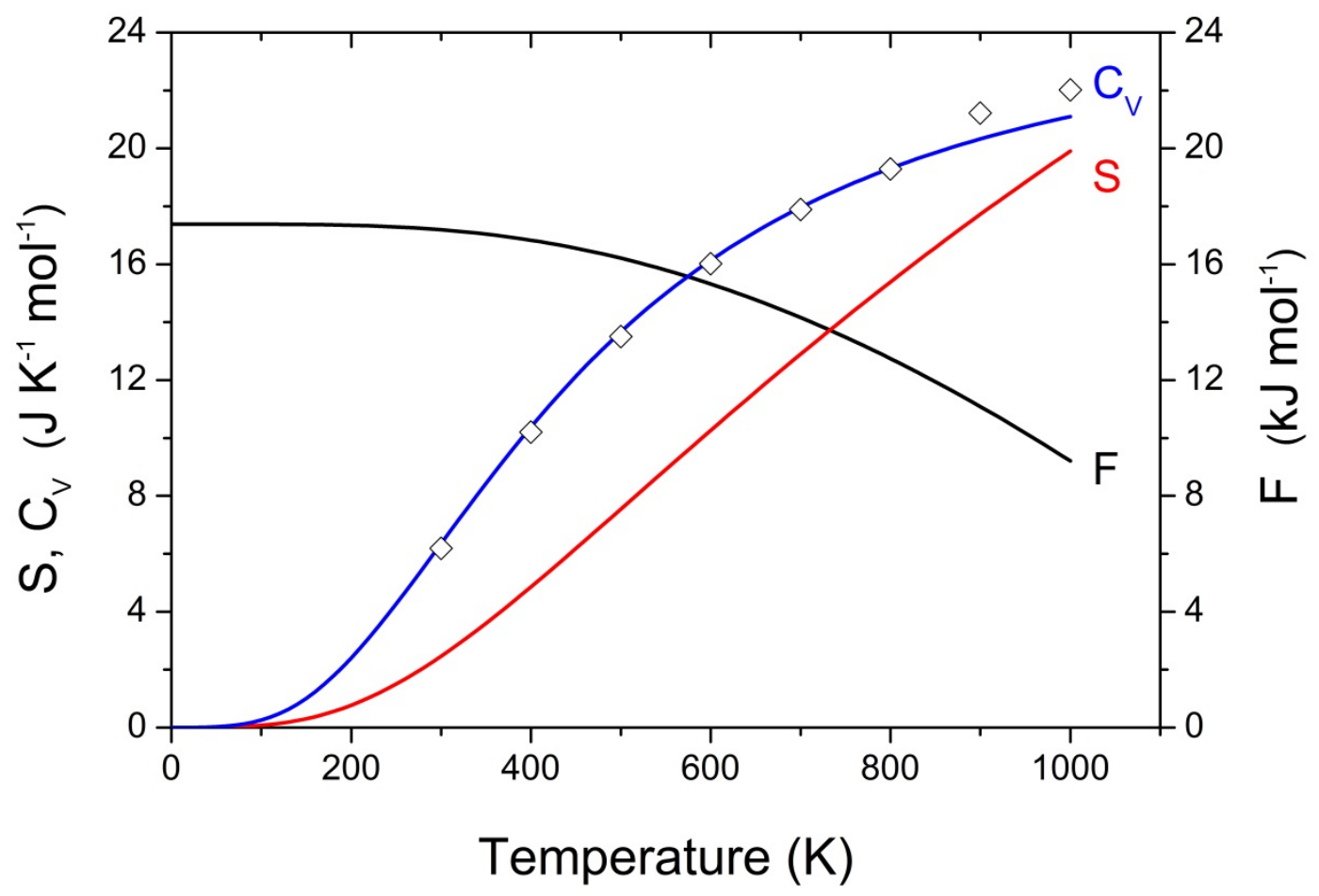

a)

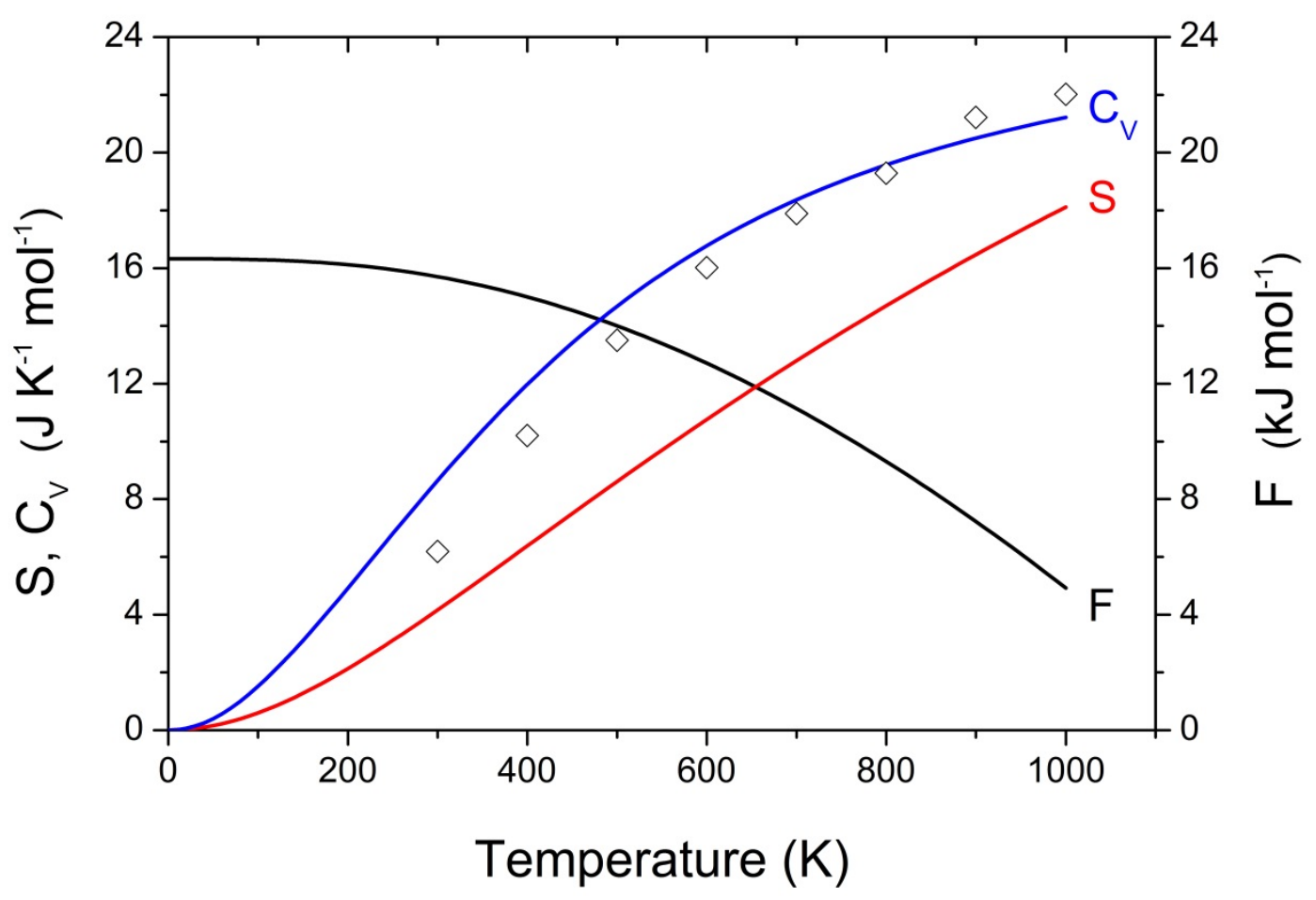

b)

Fig. 4 Thermal properties (free energy F, entropy $\mathrm{S}$ and specific heat $\mathrm{C}_{\mathrm{V}}$ at constant volume) as functions of temperature: a) diamond; the experimental $C_{v}$ values from Ref. [38] are shown as open symbols; b) trigonal $\mathrm{C}_{6}$; the results are shown as representative of hexacarbon allotropes. 

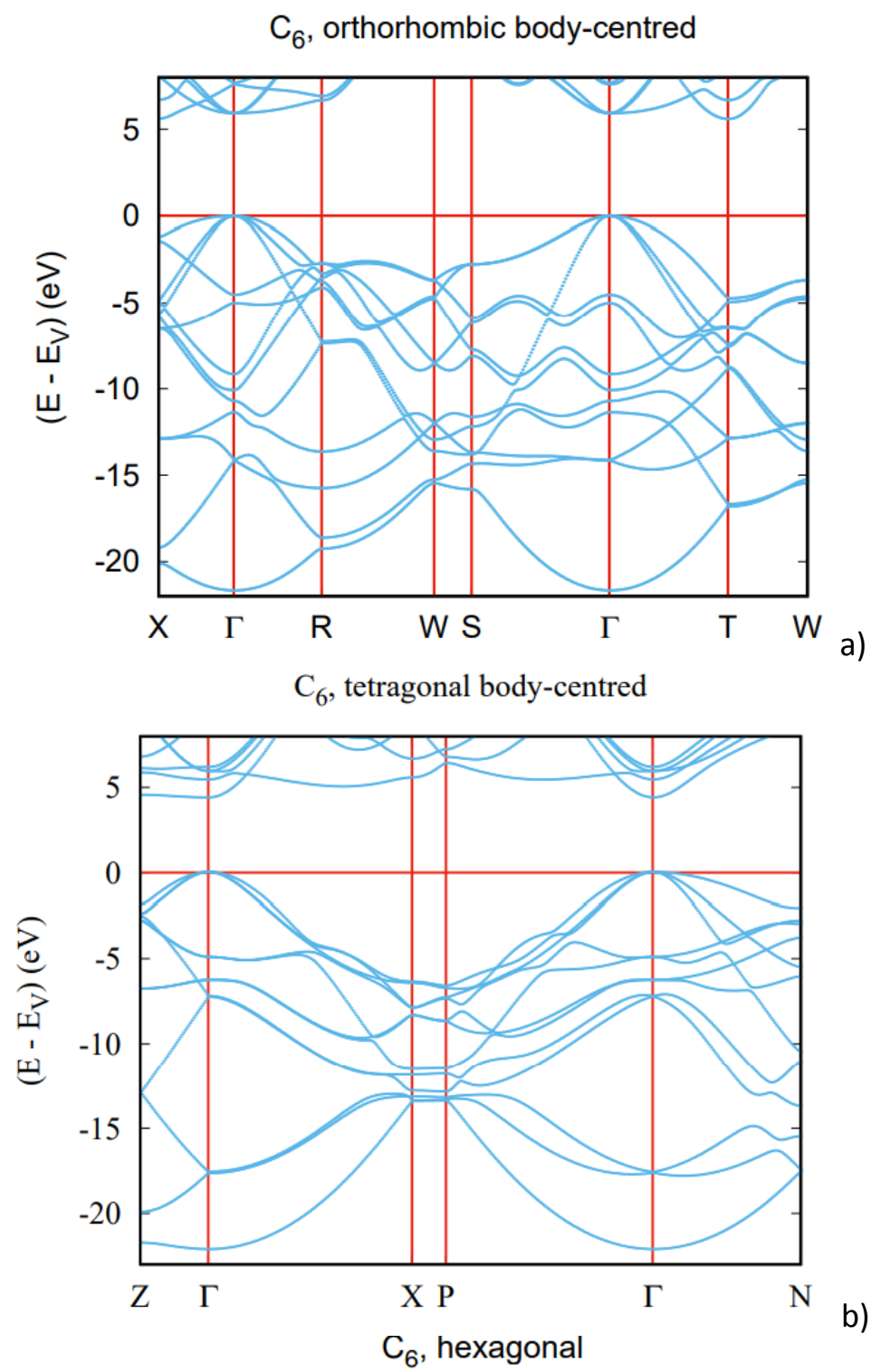

a)

b)

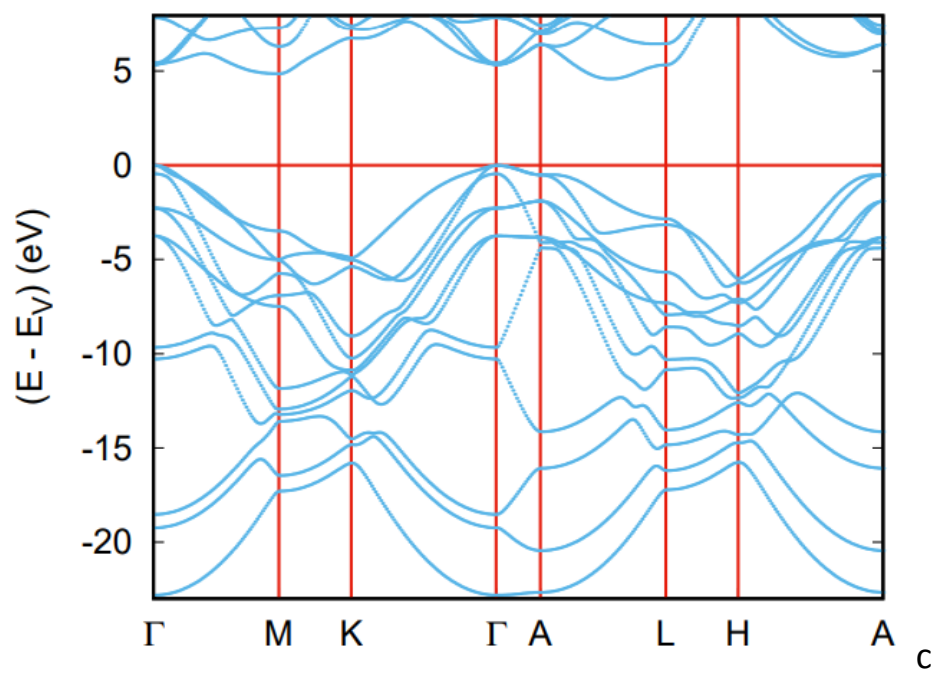

Fig. $5 \mathrm{C}_{6}$ allotropes. Electronic band structures exhibiting large band gap like diamond. 